DR ANDREW L GUNDLACH (Orcid ID : 0000-0002-6066-9692)

DR ANDRE S MECAWI (Orcid ID : 0000-0003-4517-6221)

PROFESSOR LIMEI ZHANG (Orcid ID : 0000-0002-7422-5136)

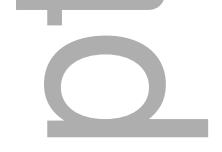

口

Article type : Review Article

\title{
Regulatory Peptides and Systems Biology: A New Era of Translational and Reverse-translational Neuroendocrinology
}

Lee E. Eiden ${ }^{1 *}$, Andrew Gundlach ${ }^{2}$, Valery Grinevich ${ }^{3}$, Mary R. Lee ${ }^{4}$, André S. Mecawi ${ }^{5}$, Duan Chen ${ }^{6}$, Ruud M. Buijs ${ }^{7}$, Vito Hernandez ${ }^{8}$, Germán Fajardo ${ }^{8}$ and Limei Zhang ${ }^{8}$

${ }^{1}$ Section on Molecular Neuroscience, National Institute of Mental Heath-Intramural Research Program, NIH, Bethesda, MD, USA; *eidenl@nih.gov

${ }^{2}$ The Florey Institute of Neuroscience and Mental Health, The University of Melbourne, Parkville, Victoria, Australia;

${ }^{3}$ Department of Neuropeptide Research in Psychiatry, Central Institute of Mental Health, University Heidelberg, Mannheim, Germany;

${ }^{4}$ Section on Clinical Psychoneuroendocrinology and Neuropsychopharmacology, NIAAA and NIDA, NIH, Bethesda, MD, USA;

${ }^{5}$ Laboratory of Neuroendocrinology, Department of Biophysics, Escola Paulista de Medicina, Universidade Federal de São Paulo, São Paulo, Brazil;

This is the author manuscript accepted for publication and has undergone full peer review but has not been through the copyediting, typesetting, pagination and proofreading process, which may lead to differences between this version and the Version of Record. Please cite this article as doi: $\underline{10.1111 / J N E .12844}$

This article is protected by copyright. All rights reserved 
${ }^{6}$ Department of Clinical and Molecular Medicine, Norwegian University of Science and Technology, Trondheim, Norway;

${ }^{7}$ Department of Cell Biology and Physiology , Institute for Biomedical Research, Universidad Nacional Autonoma de Mexico, Mexico City , Mexico;

${ }^{8}$ Facultad de Medicina, Universidad Nacional Autónoma de México, Mexico City, Mexico.*limei@unam.mx

${ }^{*}$ Corresponding authors

\section{Abstract}

Recently, there has been a resurgence in regulatory peptide science due to three converging trends. The first is the increasing population of the drug pipeline with peptide-based therapeutics, mainly in, but not restricted to, incretin-like molecules for treatment of metabolic disorders such as diabetes. The second is the development of genetic and optogenetic tools enabling new insights into how peptides actually function within brain and peripheral circuits to accomplish homeostatic and allostatic regulation. The third is the explosion in defined structures of the G-protein coupled receptors to which most regulatory peptides bind and exert their actions. These trends have closely wedded basic systems biology to drug discovery and development, creating a 'two-way street' on which translational advances travel from basic research to the clinic, and, equally importantly, 'reverse-translational' information is gathered, about the molecular, cellular and circuit-level mechanisms of action of regulatory peptides, information required for fine-tuning of drug development through testing in animal models. This Perspective focuses on a small group of 'influential' peptides, including oxytocin, vasopressin, PACAP, ghrelin, relaxin-3 and GLP-1, and how basic discoveries and their application to therapeutics have intertwined over the past decade.

This article is protected by copyright. All rights reserved 
On August $10^{\text {th }}, 2019$, the Council of the International Regulatory Peptide Society (IRPS) met on the campus of the Autonomous National University of Mexico (UNAM), Mexico City, to inaugurate the IRPS as a non-profit society and to plan future meetings of RegPep, the Society's biennial meeting. A workshop held the previous day, and co-sponsored by UNAM and the IRPS, gathered together Council members to define the Society's vision for supporting and nurturing basic and translational regulatory peptide science. This vision was developed by considering some prototype regulatory peptides and approaches to their pharmacology. The workshop, entitled "Peptide Regulation in Systems Biology and Its Translational Opportunities" was designed to create a framework within which common goals of regulatory peptide physiologists, pharmacologists, biochemists, and structural biologists could be defined and future strategies developed. During the two days of activities, the IRPS also decided to seek an appropriate sponsoring journal with which to collaborate in publishing the Society's future proceedings. Accordingly, JOURNAL OF NEUROENDOCRINOLOGY was identified, the stated mission and scope of which closely matches that of the IRPS. To this end, this Perspective is intended as a manifesto for the IRPS and an announcement of its association with JOURNAL OF NEUROENDOCRINOLOGY.

\section{Introduction: the significance of 'regulatory'}

Regulatory peptides are first messengers, released from neurons or endocrine cells, that interact with receptors on the same or immediately adjacent cells (as paracrine or autocrine factors), on synaptically-linked cells (as neurotransmitters or neuroeffectors), or on distant cells (as hormones). Regulatory peptides, along with non-peptide hormones, steroids and metabolic intermediates including glucose and various lipids and metabolites, control the dynamics of communication between cells, contained in different organs, that defines systems physiology. The 'regulatory' aspect of regulatory peptides, however, is not contained just in their bioactivity upon release from their sites of synthesis. Rather, their availability to act in a regulatory manner at distant sites is first and foremost determined by the rates at which they are synthesized and secreted. Classic examples include the following: (i) pulsatile release of luteinizing hormone-releasing hormone (LH-RH) leading to the ovulatory surge; (ii) upregulation of vasopressin synthesis and subsequent release upon changes in hydromineral status; (iii) the exquisitely fine-tuned secretion of insulin in response to glucose and a cohort of incretins, neurotransmitters and metabolites that converge on the beta cell of the pancreas 
through innervation and the general circulation; and (iv) the release (as neurotransmitters) from large dense-core vesicles in neurons or neuroendocrine cells only upon their appropriate stimulation by other first messengers. This can include messengers released by nerve impulses in the brain, by food in the gastrointestinal tract, or by stimuli such as pain, heat, cold, odorants, and light in the sensory nervous system.

The fact that regulatory peptides are both regulated in their secretion, and act as regulators upon secretion, creates an especially intimate interaction between their study as pharmacological and physiological entities. Pharmacological effects of peptides highlight their potential therapeutic actions, but do not always indicate when they are mimicking a physiological action. Correspondingly, physiological actions may not always translate into pharmacological ones, for example, if the dynamics of release of the endogenous peptide requires pulsatility or some other sort of episodic exposure to trigger a physiological and/or therapeutic effect.

In this Perspective, the physiological and pharmacological actions of a few key regulatory peptides - vasopressin, oxytocin, GLP-1, PACAP and relaxin-3 - are discussed with the intention of illuminating the broad scope of issues involved in translating peptide physiology, structural biology and pharmacology into potential therapeutic applications. The Perspective concludes by making the argument for 'reverse translation' as a second key ingredient in achieving accelerated progress in both basic and clinical regulatory peptide science, to the mutual benefit of these two inextricably linked areas of biomedical research.

\section{Vasopressin and Oxytocin:}

The regulatory peptides, vasopressin and oxytocin, share dual roles in mediating physiological regulation of hydromineral balance, and glucose metabolism and utilization by the brain. These homeostatic functions are in turn integrated with environmental factors and other physiological subsystems, including circadian rhythmicity, inflammation, and hormonal and autonomic feedback $[1,2]$. The intimate connections between (i) homeostatic regulation of salt excretion 
via control of kidney function by both vasopressin and oxytocin, and (ii) water intake, via control of consciousness of thirst, are an exquisite example of this integration at the level of the organism (see, e.g., [3]). In mammals, the neural circuitry for homeostatic regulation involves control of secretion of the posterior pituitary hormones from hypothalamus into the general circulation, monitoring of blood tonicity by the circumventricular organs (CVOs) and control of seeking behavior (thirst) by central nervous system (CNS) neurons. These homeostatic mechanisms have their earliest origins in organisms without brains, or even a CNS, but with capability to achieve homeostasis not by altering internal processes, but by moving to more advantageous regions of the external environment [4]. In fact, evolution is an important touchstone in considering the potential functions of not only vasopressin and oxytocin, but of regulatory peptides in general as a metazoan messenger class, especially when considering peptide physiology in commonly used animal models, compared to human subjects.

Vasopressin and oxytocin are also involved in the prioritization of homeostatic drives by environmental factors. This prioritization - of often competing drives - is subsumed under the concept of allostatic regulation, and includes anticipatory thirst as well as evaluation of salience of aversive environmental cues [5]. It is noteworthy that the control of vasopressinergic and oxytocinergic neurons and neurosecretory cells in these processes occurs in brain regions that may be either within or outside the blood-brain-barrier (BBB). This should be considered in the design of drugs that affect homeostatic and allostatic mechanisms in the periphery, at the BBB, and within the BBB. Environmental factors, including circadian, metabolic and gonadal status also affect the sensitivity of vasopressin- and other peptide-containing circuits [1, 6-8]. In some cases, the responsivity of peptidergic circuits as a function of inflammation or blood glucose levels can be quite marked. These factors should be taken into account when considering how drug treatments, particularly those directed at peptide receptor targets, should be tailored to individual subjects, and treatment regimens, in clinical trials for new neurotherapeutic drugs.

The involvement of oxytocin in specific behaviors, in addition to its well-known peripheral role(s) in reproductive functions, was highlighted in the Workshop. The role of oxytocinergic 
neurotransmission in the extended amygdala and hypothalamus has been explored using optogenetic and chemogenetic physiological approaches. These have revealed a dynamic role for this peptide in both effecting neurotransmission controlling real-time locomotor activity in response to environmental drives, and in the plasticity of neuronal circuits that allows the linkage of past experience to the likelihood of future responses to a given primary sensory stimulus [9-11]. Real time changes in firing rates of peptidergic neurons are beginning to provide exceedingly clear information about what peptides do where, and when. Translating this information into increasingly sophisticated operational (including behavioral) tests for drug target engagement, and prediction of behavioral outcomes across a broad range of subject environments, will be a goal of future translational research in the regulatory peptide domain. In that regard, recent data have indicated that oxytocin administered intranasally, and resulting in increased cerebrospinal fluid concentrations of the peptide, affects methylphenidate modulation of consummatory behavior $[12,13]$. Where does oxytocin actually act to produce modulation of psychomotor stimulant effects? Determining the penetrance to brain of exogenously administered peptide will provide clues as to what brain regions are actually required for target engagement for a given therapeutic application of a peptide. This type of reverse translation-oriented experimentation can provide another level of peptide specificity through pharmacodynamics - relevant to peptide-based drug development.

\section{Incretins: Obesity and Diabetes:}

The worldwide obesity epidemic represents a clear and present health threat. Current interventions and treatments of obesity include lifestyle and dietary modifications, pharmacotherapy and bariatric surgery. In fact, bariatric surgery (including gastric bypass, sleeve gastrectomy and biliopancreatic diversion) is so far the only intervention showing a longterm therapeutic effect in obesity. However, the surgical approach cannot possibly meet obesity-associated clinical/public health need in any country, developed or otherwise, across the globe. Thus, understanding the mechanisms of weight loss behind bariatric surgery will help us in translating this knowledge into less or noninvasive treatments, such as regulatory peptidebased therapies [14]. Parenthetically, the notion that patients might choose surgery, with all its 
attendant risks and complications, well illustrates that hyperphagia as a cause of obesity is a deeply rooted and highly physiological disorder that is resistant to simple voluntary restriction of caloric intake. This highlights the emerging understanding of eating as a potentially disordered behavior with behavioral components which may involve the brain circuitry also implicated in addiction, such as to drugs of abuse $[15,16]$.

Along with a rise in obesity, the prevalence of type 2 diabetes (T2D) is rapidly increasing and bariatric surgery has been documented to lead to rapid remission of T2D. However, curing all diabetics by bariatric surgery is impossible: bariatric surgery is life-changing and so not suitable for many individuals; it is expensive; and it remains risky. Therefore, analogous to obesity, identification of the underlying mechanism behind surgery-induced remission of T2D would open up avenues to develop non-surgical therapies that could potentially cure T2D.

At this time, an increasing number of regulatory peptide-based drugs for the treatment of T2D are entering the drug pipeline [17]. Clinical experience with these compounds, primarily incretin peptides, in T2D treatment has also revealed effects on weight loss, mainly through peptides acting on the GLP-1 receptor. These effects have in turn accelerated research aimed at better understanding the role(s) of peptides of both hypothalamic and ascending brain stem systems in regulating both feeding (fuel intake) and metabolism (fuel utilization and storage). The involvement of 'incretins' at both peripheral and central loci, and in both homeostatic and allostatic function, is a scenario likely to stimulate drug discovery in the regulatory peptides in coming decades, and in multiple therapeutic areas.

\section{PACAP: An Embarrassment of Regulatory Riches:}

Oxytocin and vasopressin are two regulatory peptides with a dual role in descending hormone/pituitary system function, and as an ascending neurotransmitter in behavioral/allostatic function. Pituitary adenylate cyclase-activating polypeptide (PACAP), on the other hand, is even more widely distributed, throughout the autonomic nervous system, the hypothalamus, and the extrahypothalamic brain, providing additional challenges to 
integrating its physiological function and neuroanatomy $[18,19]$. Thus, detailed optogenetic analysis of PACAP function, compared to OT and AVP, is less advanced. Nevertheless, work proceeding in this area with PACAP points to the comprehensiveness of its actions in stress responses. The actions of PACAP illustrate a second major theme for regulatory peptides of the nervous system in particular. Regulatory peptides in both brain and peripheral nervous system are almost invariably co-stored with either excitatory or inhibitory classical neurotransmitters, including glutamate and GABA in CNS [20,21] and acetylcholine in the periphery [22].

A conundrum presented by some regulatory peptides is that their actions are sufficiently versatile that both antagonists and agonists for the same receptor(s) can be envisioned. This is the case for PACAP, which has been implicated in migraine (antagonist treatment at PACAP receptor(s) would be required [23, 24]), depression and anxiety (antagonist treatment would be required $[19,25,26])$, atherosclerosis (antagonist treatment would be required [27]), tissue ischemia (agonist treatment would be required [28-31]) and stroke (agonist treatment would be required [32-38]). A potential solution to this conundrum is the exploration of greater specificity of action of exogenous peptides at sites of action for which either antagonism or agonism is the goal. Ligands biased for alternative signaling from a given peptide receptor is a second solution, and one that is being vigorously pursued in development of non-addictive opiate agonists [39]. Here, it is critical to remember that any biased agonist is by definition an antagonist for the corresponding non-stimulated pathway [40], and thus may have multiple and complex effects.

\section{Relaxin: A prototype 'brain stem ascending' regulatory peptide:}

The relaxin-3/RXFP3 system represents another example of a modulatory peptide/receptor system which is versatile in function $[41,42]$, but with a far more discrete, restricted anatomical distribution of peptide-positive neurons in the brain than many other peptides [41]. Indeed a broad network of relaxin-3-containing neuronal projections arise from several small groups of neurons in the midbrain and brainstem, with the largest and best-characterized located within the nucleus incertus $(\mathrm{NI})$ and others within the pontine raphe nucleus and the ventrolateral 
PAG [43]. NI relaxin-3 neurons are responsive to peripheral and sensory and stress-related inputs [44], and project widely to RXFP3 (the relaxin-3 receptor)-rich areas throughout the brain, where they influence arousal [45], hypothalamic, limbic and sensory activity [46, 47], and spatial memory and navigation via interactions with the septohippocampal system $[41,48,49]$. The pharmacology of RXFP3 [50], has progressively developed over the last decade, driven by the production of RXFP3-selective chimeric, truncated, stapled and single-chain peptides [51, 52], and the recent report of a potent, small organic molecule agonist [53]. These important tools, which include a viral-based RXFP3 agonist delivery system [54], along with a range of appropriate transgenic mouse lines $[55,56]$, will continue to assist proof-of-concept studies to evaluate the involvement of RXFP3 signaling in various aspects of physiology and behavior, and in clinical CNS disorders [57]. In turn these studies should foster further investigations of the ability of RXFP3-related drugs to effectively treat psychiatric illnesses for which the RXFP3 signaling system emerges as a viable target [58].

Thus, some of the lessons of GLP-1 and relaxin-3-related drug development are shared ones. In both systems, the potential for biased ligands of greater specificity is currently unclear due to the paucity of knowledge about the second messenger systems used by GLP-1 and relaxin receptors in different regions of the brain, although biased signaling has recently been investigated for RXFP3 and for relaxin at its cognate receptor RXFP1, in cell based assays. Therefore this is an area of future research in which investigators in both basic and applied realms can profitably contribute.

\section{Physiology meets drug delivery: BBB, CVOs and common peptides at periphery and brain:}

Access to the CNS is essential for the regulatory function of several circulating peptides. Indeed, some circulating regulatory peptides were demonstrated to directly cross the BBB, such as leptin, angiotensin (ANG) II, oxytocin, PACAP, and ghrelin, via changes in permeability, specific transporters at the BBB, or mechanisms as yet unknown [12, 59-61]. In addition, other 
regulatory peptides act indirectly, rather than via penetration to CNS parenchymal receptors, to modulate neuronal function. Such indirect pathways involve the CVOs and/or vagal afferents. The CVOs are brain structures that lack a BBB and express a number of receptors for circulating signals, being able to sense the blood-borne levels of several regulatory peptides [62, 63]. Similarly, vagal afferents also express a variety of receptors for circulating regulatory peptides, actively transporting receptor proteins to nerve terminals, and collecting information about local and circulating peptide levels [64, 65](Egerod et al., 2018). Information about peripheral regulatory peptides is integrated with other CNS inputs at the CVOs and/or the nucleus tractus solitarius of the brain stem (NTS) (from vagal afferents). These brain nuclei are responsible for onward transmission to those areas of the brain controlling vegetative function and behavior, to deliver adequate neuroendocrine responses to the fluctuation of the regulatory peptides in the periphery. Besides directly crossing the $\mathrm{BBB}$, and indirect action through the CVOs and vagal afferents, some peripheral regulatory peptides are also synthesized and synaptically released in the CNS, including gastrin, CCK, GIP, and GLP-1 $[66,67]$.

Naturally, with multiple modes of regulation available to various peptides, whether or not CNS synthesis and synaptic release is required for the CNS action of a peptide in a given circumstance can be uncertain. Whether and when ghrelin and ANG II are actually released within the CNS, for example, has been a matter of controversy $[68,69]$. The use of 'sniffer cell' and other in vivo detection methods for assessment of peptide secretion in CNS are helping to answer these questions [70]. By using the sniffer cell approach, for example, Farmer et al. (2019) have recently demonstrated synaptic release of ANG II at the median preoptic nucleus by either electrical or optogenetic stimulation of the subfornical organ [71].

In those cases in which peptides act peripherally, and on the brain indirectly via the CVOs, and directly as transmitters in the brain, it can be difficult to know (i) how the brain integrates these parallel information streams, (ii) whether therapeutic agents are acting centrally or peripherally, and (iii) whether, therefore, we can build adequate physiological models for peptide action on which to base therapeutic interventions. The case of GLP-I is instructive here: 
this peptide is secreted peripherally, is present at synapses onto neurons of the NTS that express both the GLP-1 receptor and GLP-1 itself, and this 'upwardly mobile' projection system acts in ventral tegmentum and other di- and telecephalic brain regions to mediate GLP-1dependent food-specific appetitive behavior. For these reasons, it was initially difficult, as for ghrelin, to determine whether GLP-1 actions are primarily peripheral, primarily central, or necessarily both, for a given physiological or behavioral response. It is noteworthy that this 'peptides-in-series' arrangement also exists for PACAP presence in both primary sensory inputs to CNS, as well as within cells upon which the latter first synapse in the brain (Zhang et al., unpublished, 2020).

\section{Regulatory peptides, inflammation and immune regulation, and neuroendocrinology}

Evolution, by definition, involves the use of all the gene-encoded molecular and cellular tools available to existing organisms to maximize fitness [72]. Thus, it is not surprising that the peptides we refer to as 'neuroendocrine regulatory peptides' have additional roles outside of the realm of what we have chosen to call 'neuroendocrinology'. Examples include the roles of vasopressin and oxytocin in the thymus during self-tolerance $[73,74]$, roles of chromogranin peptides in autoimmune defense and disease [75], and the role of PACAP in vascular and neural inflammation via elaboration by antigen-presenting cells including microglia and monocyte/macrophages [76-78]. We are likely to find in future that these functions, appearing now to stand alone from neuroendocrinology as generally construed, are also intimately involved in neuroendocrine regulation. Systems physiology dictates that integration, rather than insulation, is the default relationship among the systems of the body, as amply illustrated by the opening example of circadian regulation of neuroendocrine susceptibility to cytokine regulation $[1,8]$. Perceiving regulatory peptides as first messengers that allow multi-cellular organisms to coordinate their activities as a single entity is an inclusive, yet 'neuroendocrinecentric', viewpoint. It is likely to be a productive one in moving forward our basic understanding of mammalian physiology as an evolved enterprise, and to quickly grasp how to employ new insights into neuroendocrine function into therapeutic applications. 


\section{The role of translation and reverse translation/reversible translation in regulatory peptide physiology and clinical application:}

Environmental drivers of human behavior range from the daily appearance of the sun to the availability of food and water, interaction with other humans and domesticated mammals, and the vagaries of wind, rain and temperature that determine where human activities take place. The environment is reflected internally in the homeostatic mechanisms that promote the onset and cessation of eating, drinking, sexual behavior, and sleep, and are signaled by hunger, thirst, libido and fatigue. It is increasingly obvious to physiologists, that anticipatory behaviors, referred to as allostatic regulation, are linked to homeostatic drives by regulatory peptides acting in the realms of reward and aversion, triggering behaviors of seeking and avoidance. The Workshop reflected, and the IRPS aims to nurture, a growing interest worldwide in understanding the properties of peptide ligand-receptor dyads in integrating virtually every aspect of mammalian physiology. Metabolic, hydromineral, sensory, and social cues are linked to the prioritization of consummatory behaviors that we recognize best when they are disrupted in disorders such as obesity, anxiety, post-traumatic stress disorder (PTSD), alcoholism, drug addiction, and depression, and even in some everyday events such as sickness behavior and insomnia. The secretion of peptides from cells in the gut, adipose tissue, peripheral nervous system and brain, to sets of receptors on recipient cells, after traveling short (as neurotransmitters) or long (as hormones) distances, completes a plethora of circuits required for normal human behavior. We are beginning to map and understand each of them, and the unique properties of each that offer opportunities for translation to clinical practice in a wide range of human disorders.

How do we meet the challenge of the ever-expanding roles of peptides in physiology, and the need to create ever more selective compounds for specific clinical applications? A few thoughts are worth considering. One, is that, as already alluded to, peptides and their receptors have coevolved, but with remarkable conservation of function $[79,80]$. This is seen quite vividly in the utilization of peptide signaling for both homeostatic and allostatic function in the regulation of 
water intake and vasopressinergic signaling $[5,81]$. Thus, it is incumbent upon scientists hinting at potential clinical applications of a given peptidergic system for a given disease, to specify, empirically, that the ligand-receptor dyad of interest is, in fact, embedded in the human central and/or peripheral nervous system within the same circuits identified in animal models. Often, this is not the case [82], and human 'exceptionalism' can be used to determine the best strategies for targeting a particular clinical problem in which multiple peptides may contribute. A second consideration is that peptide actions are almost invariably combinatorial, and this is most true when the function of interest is most primordial. Hunger, thirst and sex are existential drives for all species. The genomic niche constituted by the regulatory peptides and their receptors has clearly contributed substantially throughout the history of genetic selection (evolution), and in highly species-specific ways, to both regulating these drives homeostatically, and prioritizing the behaviors driven by each. The recent development of chimeric peptides that engage multiple peptidergic receptors for controlling glucose utilization/insulin secretion provide an example of how engaging multiple players in the regulatory peptide orchestra might yield clinically impactful results [15]. Adjudication of issues raised by clinical translation, in animal models, is a currently somewhat neglected area in regulatory peptide research. As an example, the genetic link between variation in the estrogen responsive element of the PACAP PAC1 receptor, and PTSD progression in female human subjects [83], has yet to find an analog in a sex-specific stress response in rodents. This may be due to a species-specific PACAP action in the human compared to rat or mouse, or a failure of reverse-translation to prioritize the identification of a corresponding rodent sex-specific function for this neuropeptide in the basic physiology of stress and fear learning. However, it is likely that the issue of reverse translation will arise again and again, with important implications for both basic and translational research, in the regulatory peptide arena. The notion that translation is ever a one-way street from basic science to the clinic, as currently conceptualized, rather than an informed dialog, is one that regulatory peptide practitioners should look forward to jettisoning.

\section{Acknowledgements:}


We thank the administration of the Facultad de Medicina, UNAM for sponsorship of the August 9, 2019 Workshop as well as the Workshop on Peptide Drug Development, RegPep2018, Acapulco Diamante that preceded and inspired it. More information about both is available at the IRPS website<regpep.org>.

\section{References:}

1. Buijs, R.M., et al., The suprachiasmatic nucleus; a responsive clock regulating homeostasis by daily changing the setpoints of physiological parameters. Auton Neurosci, 2019. 218: p. 43-50.

2. Chrousos, G.P., Stress and disorders of the stress system. Nat Rev Endocrinol, 2009. 5(7): p. 374-81.

3. Greenwood, M.P., et al., A comparison of physiological and transcriptome responses to water deprivation and salt loading in the rat supraoptic nucleus. Am J Physiol Regul Integr Comp Physiol, 2015. 308(7): p. R559-68.

4. Beets, I., et al., Ancient neuromodulation by vasopressin/oxytocin-related peptides. Worm, 2013. 2(2): p. e24246.

5. Gizowski, C., C. Zaelzer, and C.W. Bourque, Clock-driven vasopressin neurotransmission mediates anticipatory thirst prior to sleep. Nature, 2016. 537(7622): p. 685-8.

6. Kalsbeek, A., et al., Suprachiasmatic GABAergic inputs to the paraventricular nucleus control plasma glucose concentrations in the rat via sympathetic innervation of the liver. J. Neurosci., 2004. 24(35): p. 7604-7613.

7. Kalsbeek, A., et al., Circadian disruption and SCN control of energy metabolism. FEBS Lett, 2011. 585(10): p. 1412-26.

8. Buijs, F.N., et al., The Circadian System: A Regulatory Feedback Network of Periphery and Brain. Physiology (Bethesda), 2016. 31(3): p. 170-81.

9. Grinevich, V. and R. Stoop, Interplay between Oxytocin and Sensory Systems in the Orchestration of Socio-Emotional Behaviors. Neuron, 2018. 99(5): p. 887-904. 
10. Hasan, M.T., et al., A Fear Memory Engram and Its Plasticity in the Hypothalamic Oxytocin System. Neuron, 2019. 103(1): p. 133-146 e8.

11. Grund, T., et al., Chemogenetic activation of oxytocin neurons: Temporal dynamics, hormonal release, and behavioral consequences. Psychoneuroendocrinology, 2019. 106: p. 77-84.

12. Lee, M.R., et al., Oxytocin by intranasal and intravenous routes reaches the cerebrospinal fluid in rhesus macaques: determination using a novel oxytocin assay. Mol Psychiatry, 2018. 23(1): p. 115-122.

13. Lee, M.R., et al., Effect of systemically administered oxytocin on dose response for methylphenidate self-administration and mesolimbic dopamine levels. Ann N Y Acad Sci, 2019. 1455(1): p. 173-184.

14. Olsen, M.K., et al., New Approaches for Weight Loss: Experiments Using Animal Models. Curr Pharm Des, 2018. 24(18): p. 1926-1935.

15. Brandt, S.J., et al., Peptide-based multi-agonists: a new paradigm in metabolic pharmacology. J Intern Med, 2018. 284(6): p. 581-602.

16. Clemmensen, C., et al., Emerging hormonal-based combination pharmacotherapies for the treatment of metabolic diseases. Nat Rev Endocrinol, 2018.

17. Henninot, A., J.C. Collins, and J.M. Nuss, The Current State of Peptide Drug Discovery: Back to the Future? J Med Chem, 2018. 61(4): p. 1382-1414.

18. Mustafa, T. and L.E. Eiden, The Secretin Superfamily: PACAP, VIP and Related Peptides, in Handbook of Neurochemistry and Molecular Neurobiology: XIII. Neuroactive Peptides and Proteins, R. Lim, Editor. 2006, Springer Heidelberg. p. 1-36.

19. Jiang, S.Z. and L.E. Eiden, PACAPergic Synaptic Signaling and Circuitry Mediating Mammalian Responses to Psychogenic and Systemic Stressors, in Pituitary Adenylate Cyclase-Activating Polypeptide-PACAP, D.R.a.A. Tamas, Editor. 2016, Springer International: Switzerland.

20. Beaule, C., et al., Temporally restricted role of retinal PACAP: integration of the phaseadvancing light signal to the SCN. J Biol Rhythms, 2009. 24(2): p. 126-34. 
21. Zhang, L. and L.E. Eiden, Two ancient neuropeptides, PACAP and AVP, modulate motivated behavior at synapses in the extrahypothalamic brain: a study in contrast. Cell Tissue Res, 2019. 375(1): p. 103-122.

22. Hamelink, C., et al., Pituitary adenylate cyclase activating polypeptide is a sympathoadrenal neurotransmitter involved in catecholamine regulation and glucohomeostasis. Proc. Natl. Acad. Sci. USA, 2002. 99: p. 461-466.

23. Zagami, A.S., L. Edvinsson, and P.J. Goadsby, Pituitary adenylate cyclase activating polypeptide and migraine. Ann Clin Transl Neurol, 2014. 1(12): p. 1036-40.

24. Rubio-Beltran, E., et al., PACAP38 and PAC1 receptor blockade: a new target for headache? J Headache Pain, 2018. 19(1): p. 64.

25. Kormos, V. and B. Gaszner, Role of neuropeptides in anxiety, stress, and depression: from animals to humans. Neuropeptides, 2013. 47(6): p. 401-19.

26. Mustafa, T., et al., Impact of PACAP and PAC1 receptor deficiency on the neurochemical and behavioral effects of acute and chronic restraint stress in male C57BL/6 mice. Stress, 2015. 18(4): p. 408-418.

27. Rasbach, E., et al., PACAP deficiency aggravates atherosclerosis in ApoE deficient mice. Immunobiology, 2018.

28. Rabl, K., et al., PACAP inhibits anoxia-induced changes in physiological responses in horizontal cells in the turtle retina. Regul. Pept., 2002. 109(1-3): p. 71-74.

29. Horvath, G., et al., Mice deficient in neuropeptide PACAP demonstrate increased sensitivity to in vitro kidney hypoxia. Transplant Proc, 2010. 42(6): p. 2293-5.

30. Atlasz, T., et al., Evaluation of the protective effects of PACAP with cell-specific markers in ischemia-induced retinal degeneration. Brain Res Bull, 2010. 81(4-5): p. 497-504.

31. Szakaly, P., et al., Effects of PACAP on survival and renal morphology in rats subjected to renal ischemia/reperfusion. J Mol Neurosci, 2008. 36(1-3): p. 89-96.

32. Hori, M., et al., Transcriptomics and proteomics analyses of the PACAP38 influenced ischemic brain in permanent middle cerebral artery occlusion model mice. J Neuroinflammation, 2012. 9: p. 256. 
33. Ohtaki, H., et al., Role of PACAP in ischemic neural death. J Mol Neurosci, 2008. 36(1-3): p. 16-25.

34. Vaudry, D., et al., PACAP protects cerebellar granule neurons against oxidative stressinduced apoptosis. Eur. J. Neurosci., 2002. 15(9): p. 1451-1460.

35. Dejda, A., et al., PACAP and a novel stable analog protect rat brain from ischemia: Insight into the mechanisms of action. Peptides, 2011. 32(6): p. 1207-16.

36. Reglodi, D., et al., Neuroprotective effects of PACAP38 in a rat model of transient focal ischemia under various experimental conditions. Ann N Y Acad Sci, 2000. 921: p. 119-28.

37. Chen, Y., et al., Neuroprotection by endogenous and exogenous PACAP following stroke. Regul Pept, 2006. 137(1-2): p. 4-19.

38. Lazarovici, P., et al., Multimodal neuroprotection induced by PACAP38 in oxygen-glucose deprivation and middle cerebral artery occlusion stroke models. J Mol Neurosci, 2012. 48(3): p. 526-40.

39. Bohn, L.M., et al., Enhanced morphine analgesia in mice lacking beta-arrestin 2. Science, 1999. 286(5449): p. 2495-8.

40. Shenoy, S.K. and R.J. Lefkowitz, Angiotensin II-stimulated signaling through G proteins and beta-arrestin. Sci STKE, 2005. 2005(311): p. cm14.

41. Ma, S., et al., Distribution, physiology and pharmacology of relaxin-3/RXFP3 systems in brain. Br J Pharmacol, 2017. 174(10): p. 1034-1048.

42. Olucha-Bordonau, F.E., et al., Modulation of forebrain function by nucleus incertus and relaxin-3/RXFP3 signaling. CNS Neurosci Ther, 2018. 24(8): p. 694-702.

43. Ma, S., et al., Relaxin-3 in GABA projection neurons of nucleus incertus suggests widespread influence on forebrain circuits via G-protein-coupled receptor-135 in the rat. Neuroscience, 2007. 144(1): p. 165-90.

44. Walker, L.C., et al., Nucleus incertus corticotrophin-releasing factor 1 receptor signalling regulates alcohol seeking in rats. Addict Biol, 2017. 22(6): p. 1641-1654.

45. Ma, S. and A.L. Gundlach, Ascending control of arousal and motivation: role of nucleus incertus and its peptide neuromodulators in behavioural responses to stress. J Neuroendocrinol, 2015. 27(6): p. 457-67. 
46. de Avila, C., et al., Effects of chronic silencing of relaxin-3 production in nucleus incertus neurons on food intake, body weight, anxiety-like behaviour and limbic brain activity in female rats. Psychopharmacology (Berl), 2020.

47. Furuya, W.I., et al., Relaxin-3 receptor (RXFP3) activation in the nucleus of the solitary tract modulates respiratory rate and the arterial chemoreceptor reflex in rat. Respir Physiol Neurobiol, 2020. 271: p. 103310.

48. Ganella, D.E., S. Ma, and A.L. Gundlach, Relaxin-3/RXFP3 Signaling and Neuroendocrine Function - A Perspective on Extrinsic Hypothalamic Control. Front Endocrinol (Lausanne), 2013. 4: p. 128.

49. Ryan, P.J., et al., Nucleus incertus--an emerging modulatory role in arousal, stress and memory. Neurosci Biobehav Rev, 2011. 35(6): p. 1326-41.

50. Bathgate, R.A., et al., Relaxin family peptides and their receptors. Physiol Rev, 2013. 93(1): p. 405-80.

51. Marwari, S., et al., Intranasal administration of a stapled relaxin-3 mimetic has anxiolytic-and antidepressant-like activity in rats. Br J Pharmacol, 2019. 176(20): p. 3899-3923.

52. Praveen, P., et al., Single chain peptide agonists of relaxin receptors. Mol Cell Endocrinol, 2019. 487: p. 34-39.

53. DeChristopher, B., et al., Discovery of a small molecule RXFP3/4 agonist that increases food intake in rats upon acute central administration. Bioorg Med Chem Lett, 2019. 29(8): p. 991-994.

54. Ganella, D.E., et al., Increased feeding and body weight gain in rats after acute and chronic activation of RXFP3 by relaxin-3 and receptor-selective peptides: functional and therapeutic implications. Behav Pharmacol, 2012. 23(5-6): p. 516-25.

55. Hosken, L.T., et al., Relaxin-3 receptor (Rxfp3) gene knockout mice display reduced running wheel activity: implications for role of relaxin-3/RXFP3 signalling in sustained arousal. Behav Brain Res, 2015. 278: p. 167-75.

56. Smith, C.M., et al., Relaxin-3 null mutation mice display a circadian hypoactivity phenotype. Genes Brain Behav, 2012. 11(1): p. 94-104. 
57. Kumar, J.R., et al., Relaxin' the brain: a case for targeting the nucleus incertus network and relaxin-3/RXFP3 system in neuropsychiatric disorders. Br J Pharmacol, 2017. 174(10): p. 1061-1076.

58. Van Der Westhuizen, E.T., et al., Relaxin receptors--new drug targets for multiple disease states. Curr Drug Targets, 2007. 8(1): p. 91-104.

59. Banks, W.A., Peptides and the blood-brain barrier. Peptides, 2015. 72: p. 16-9.

60. Biancardi, V.C., et al., Circulating angiotensin II gains access to the hypothalamus and brain stem during hypertension via breakdown of the blood-brain barrier. Hypertension, 2014. 63(3): p. 572-9.

61. Uriarte, M., et al., Evidence Supporting a Role for the Blood-Cerebrospinal Fluid Barrier Transporting Circulating Ghrelin into the Brain. Mol Neurobiol, 2019. 56(6): p. 41204134.

62. Miyata, S., New aspects in fenestrated capillary and tissue dynamics in the sensory circumventricular organs of adult brains. Front Neurosci, 2015. 9: p. 390.

63. Hindmarch, C.C. and A.V. Ferguson, Physiological roles for the subfornical organ: a dynamic transcriptome shaped by autonomic state. J Physiol, 2016. 594(6): p. 1581-9.

64. Johannessen, H., et al., Vagal Blocking for Obesity Control: a Possible Mechanism-OfAction. Obes Surg, 2017. 27(1): p. 177-185.

65. Egerod, K.L., et al., Profiling of G protein-coupled receptors in vagal afferents reveals novel gut-to-brain sensing mechanisms. Mol Metab, 2018. 12: p. 62-75.

66. Rehfeld, J.F., et al., Gastrin and cholecystokinin in pituitary neurons. Proc Natl Acad Sci U S A, 1984. 81(6): p. 1902-5.

67. Larsen, P.J., et al., Distribution of glucagon-like peptide-1 and other preproglucagonderived peptides in the rat hypothalamus and brainstem. Neuroscience, 1997. 77(1): p. 257-70.

68. Cabral, A., et al., Is Ghrelin Synthesized in the Central Nervous System? Int J Mol Sci, 2017. 18(3).

69. Uijl, E., L. Ren, and A.H.J. Danser, Angiotensin generation in the brain: a re-evaluation. Clin Sci (Lond), 2018. 132(8): p. 839-850. 
70. Nyberg, J., et al., Immunohistochemical distribution of glucose-dependent insulinotropic polypeptide in the adult rat brain. J Neurosci Res, 2007. 85(10): p. 2099-119.

71. Farmer, G.E., et al., Sniffer cells for the detection of neural Angiotensin II in vitro. Sci Rep, 2019. 9(1): p. 8820.

72. Duboule, D. and A.S. Wilkins, The evolution of 'bricolage'. Trends Genet, 1998. 14(2): p. 54-9.

73. Hansenne, I., Thymic transcription of neurohypophysial and insulin-related genes: impact upon T-cell differentiation and self-tolerance. J Neuroendocrinol, 2005. 17(5): p. 321-7.

74. Geenen, V., et al., The presentation of neuroendocrine self-peptides in the thymus: an essential event for individual life and vertebrate survival. Ann. N. Y. Acad. Sci., 2019, in press. in press.

75. Jin, N., et al., N-terminal additions to the WE14 peptide of chromogranin A create strong autoantigen agonists in type 1 diabetes. Proc Natl Acad Sci U S A, 2015. 112(43): p. 13318-23.

76. Armstrong, B.D., et al., Impairment of axotomy-induced pituitary adenylyl cyclaseactivating peptide gene expression in Thelper 2 lymphocyte-deficient mice. Neuroreport, 2006. 17(3): p. 309-12.

77. Armstrong, B.D., et al., Impaired nerve regeneration and enhanced neuroinflammatory response in mice lacking pituitary adenylyl cyclase activating peptide. Neuroscience, 2008. 151(1): p. 63-73.

78. Ringer, C., et al., PACAP signaling exerts opposing effects on neuroprotection and neuroinflammation during disease progression in the SOD1(G93A) mouse model of amyotrophic lateral sclerosis. Neurobiol Dis, 2013. 54: p. 32-42.

79. Darlinson, M.G. and D. Richter, Multiple genes for neuropeptides and their receptors: coevolution and physiology. Trends Neurosci., 1999. 22: p. 81-88.

80. Janssen, T., et al., Coevolution of neuropeptidergic signaling systems: from worm to man. Ann N Y Acad Sci, 2010. 1200: p. 1-14. 
81. Zhang, L., et al., Thirst Is Associated with Suppression of Habenula Output and Active Stress Coping: Is there a Role for a Non-canonical Vasopressin-Glutamate Pathway? Front Neural Circuits, 2016. 10: p. 13.

82. Elde, R., et al., Interspecies conservation and variation in peptidergic neurons. Peptides, 1980. 1: p. 21-26.

83. Ressler, K.J., et al., Post-traumatic stress disorder is associated with PACAP and the PAC1 receptor. Nature, 2011. 470(7335): p. 492-7.

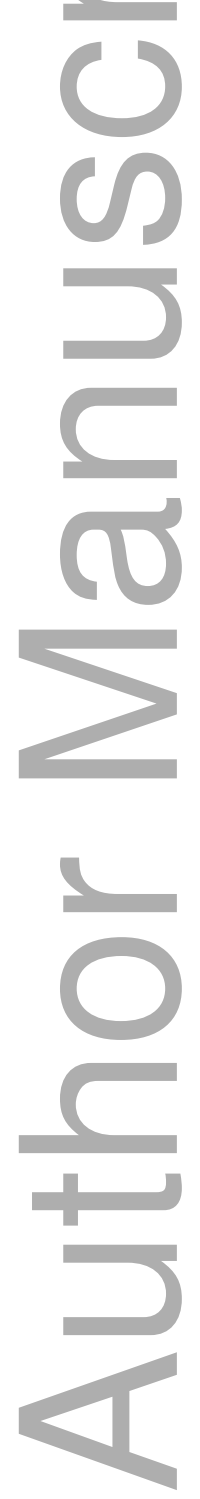

This article is protected by copyright. All rights reserved 


\section{University Library}

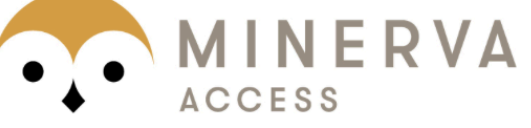

A gateway to Melbourne's research publications

Minerva Access is the Institutional Repository of The University of Melbourne

Author/s:

Eiden, LE;Gundlach, AL;Grinevich, V;Lee, MR;Mecawi, AS;Chen, D;Buijs, RM;Hernandez,

VS;Fajardo-Dolci, G;Zhang, L

Title:

Regulatory peptides and systems biology: A new era of translational and reversetranslational neuroendocrinology

Date:

2020-04-19

Citation:

Eiden, L. E., Gundlach, A. L., Grinevich, V., Lee, M. R., Mecawi, A. S., Chen, D., Buijs, R. M., Hernandez, V. S., Fajardo-Dolci, G. \& Zhang, L. (2020). Regulatory peptides and systems biology: A new era of translational and reverse-translational neuroendocrinology. JOURNAL OF NEUROENDOCRINOLOGY, 32 (5), https://doi.org/10.1111/jne.12844.

Persistent Link:

http://hdl.handle.net/11343/275654 